\title{
Situating Language in the Real-World: Authors' Reply to Commentaries
}

$\boldsymbol{E}$ journal of cognition

SPECIAL

COLLECTION:

SITUATING LANGUAGE

IN THE REAL-WORLD

COMMENTARY

] $\mathrm{u}$ [ubiquity press

YASAMIN MOTAMEDI

GABRIELLA VIGLIOCCO (D)

*Author affiliations can be found in the back matter of this article

CORRESPONDING AUTHOR:

Gabriella Vigliocco

Experimental Psychology,

University College London, GB

g.vigliocco@ucl.ac.uk

KEYWORDS:

iconicity; multimodal

communication; language

acquisition; language

processing

TO CITE THIS ARTICLE:

Murgiano, M., Motamedi, Y., \&

Vigliocco, G. (2021). Situating Language in the Real-World: Authors' Reply to Commentaries. Journal of Cognition, 4(1): 44, pp. 1-4. DOI: https://doi.

org/10.5334/joc.181 


\section{BROADENING OUR VIEW OF LANGUAGE}

In promoting an ecologically valid approach to the study of language and, more specifically, nonarbitrariness, our paper distinguished between two perspectives from which language can be studied: the 'language as a system' and the 'language as situated'. These two perspectives do not stand as alternatives; rather, in our view, the language as situated encompasses the language as a system perspective. It is a more comprehensive approach that includes all the linguistic components traditionally studied but also the multimodal, often non-arbitrary, cues that are overwhelmingly present in the moment in language use. These cues characterize the way in which language is concretely learnt and understood in the real-world. Thus, it is not surprising that, as noted by Perlman and Woodin, iconicity, which is a key feature of the language as situated view, is also present and maintained in the language as a system view. Or, as argued by Ozyurek, that systematicity and language specificity, key features of the language as a system perspective, are also found in gestures which are part of language only under a situated perspective.

The distinction between 'system' and 'situated' does not coincide with the distinction between rule-governed, conventional elements of language, and universally accessible components of communication devoid of any conventionality as implied in Ozyurek's commentary. Situated language refers to the real-world uses of language rather than universality. We argue in favor of the importance of reintegrating the observation of language use in any theoretical and empirical approach to language study. In such an approach, language cannot be divorced from the physical and communicative context or from cultural, individual and linguistic differences and iconicity cannot be thought of as an universal and direct mapping between a sign and an object. Multimodal iconic cues exploit a motivated correspondence between form and meaning through a selection of those semantic aspects that are salient in a certain physical, cultural and linguistic context. We argue that this contextually motivated mapping between form and meaning facilitates the access to the latter and consequently helps language acquisition and processing.

\section{ICONICITY IN THE SYSTEM AND ICONICITY IN THE SITUATED VIEW}

We fully agree with Perlman and Woodin that iconicity is present in those systemic and categorical parts of language in far larger extent than it has often been acknowledged in linguistic research (Hockett, 1960; Newmeyer, 1992) and that it is actively maintained (see also Vinson et al., 2021). However, the amount of iconicity is still going to be vastly underestimated unless a language as situated view is taken. Multimodal non-arbitrary cues such as gestures and prosodic modulations not only provide additional sources of iconicity, but can further modify and extend iconicity in the system. For example, research on ideophones has highlighted that the totality of their iconic expression cannot be attributed to sound symbolism in the lexeme/ morpheme alone, but in how it is used in combination with other cues such as prosody and iconic gesture (Dingemanse, 2012; Nuckolls, 1996), and that playful language use regularly creates or enhances iconic expression in context (Dingemanse and Thompson, 2020; Jakobson and Waugh, 1979; Kaneko and Sutton-Spence, 2012).

Why would iconicity be maintained in the systemic aspects of language? We suggest that iconicity is maintained because it might be beneficial in ways that are not confined to early language emergence or first language acquisition, but that represent everyday communication, for example in grounding communication, either for language learners without existing conventions or mature language users navigating a new communicative context, with iconicity being, as we explained above, not a fixed property but one that can be modulated and made salient in context.

Also, some degree of iconicity in the system (allowing for a more transparent mapping between communicative form and meaning) may simply be necessary for communicative success in non-situated contexts like when written language is used. Using methods such as lexical decision or semantic categorization on written words (as discussed by Sidhu and Pexman) taps into this type of baseline iconicity. Sidhu and Pexman also discuss the possibility that the iconicity addressed in studies of written language also tap into potential for iconicity. We disagree with this because we can have words that have very low iconicity ratings becoming iconic in situ by virtue of gestures or iconic prosody or sound effects, while the iconicity of words with high iconicity ratings is not necessarily increased in face-to-face communicative contexts. 
We cannot agree more with Emmorey who says that historically, the perspective that draws a strict line between system and situated comes from looking at spoken languages (see also Vigliocco et al., 2014). If the study of language started from the investigation of signed languages, not only would we not draw such a line, in addition we would see the system as part of the situated. She offers the perfect example of why this would be the case: the production of lexical signs in close connection with drawings or written words, environmental elements that reinforce and further explain the meaning of those signs through physical connection. We argue that spoken languages can also have a similar level of connection with external, environmental factors: we can observe an example of this with onomatopoeia, that can be articulated along with other environmental noises or sounds, or with iconic prosody with which we can for example express the length of an object while following its shape with our hand.

\section{LANGUAGE AS SITUATED AND EMBODIMENT}

What is the relationship between the broader perspective provided by the situated view of language and embodiment? This question was not discussed in the target article, but clearly is an important issue to address in the future. Our hypothesis is that the extent to which comprehenders need to simulate (i.e., develop imagistic representations based on their knowledge) what is being said depends on the level of situatedness of the communicative situation. The physical context necessarily matters in determining whether the comprehender needs to simulate: if the comprehender is watching a cooking show in which the speaker (the chef) is describing what they are doing while they are doing it, there will be less need to develop internal simulations. However, if the comprehender reads a novel, there will not be any support from the physical context and therefore greater need to develop internal simulations (Zwaan, 2014). Taking the language as situated perspective, the need (and presumably amount) of simulation that a comprehender will develop will also depend on the presence of non-arbitrary cues provided by the speaker, further reducing the need for internal simulations. Thus, words and phrases can become meaningful by virtue of eliciting the retrieval of sensorimotor and affective information from memory, as argued by Long, Chia and Kaschak. However, this may be the case only when neither the physical, nor, crucially, the communicative context provide access to sensorimotor and affective information in a more direct manner via indexical and iconic cues.

\section{ETHICS AND CONSENT}

The reply does not contain any experimental work with human subjects, I do not think this is necessary.

\section{COMPETING INTERESTS}

The authors have no competing interests to declare.

\section{AUTHOR AFFILIATIONS}

\section{Margherita Murgiano}

Experimental Psychology, University College London, GB

Yasamin Motamedi

Centre for Language Evolution, University of Edinburgh, GB

Gabriella Vigliocco (D) orcid.org/0000-0002-7190-3659

Experimental Psychology, University College London, GB

\section{REFERENCES}

Dingemanse, M. (2012). Advances in the cross-linguistic study of ideophones. Language and Linguistics compass, 6(10), 654-672. DOI: https://doi.org/10.1002/lnc3.361

Dingemanse, M., \& Thompson, B. (2020). Playful iconicity: Structural markedness underlies the relation between funniness and iconicity. Language and Cognition, 12(1), 203-224. DOI: https://doi. org/10.1017/langcog.2019.49

Emmorey, K. (2021). Environmentally-coupled signs and gestures. Journal of Cognition, 4(1), XX. DOI: https://doi.org/10.5334/joc.132 
Hockett, C. F. (1960). The origin of speech. Scientific American, 203, 88-96. DOI: https://doi.org/10.1038/ scientificamerican0960-88

Jakobson, R., \& Waugh, L. (1979). The spell of speech sounds. The Sound Shape of Language, 282-340.

Kaneko, M., \& Sutton-Spence, R. (2012). Iconicity and metaphor in sign language poetry. Metaphor and Symbol, 27(2), 107-130. DOI: https://doi.org/10.1080/10926488.2012.665794

Long, M., Chia, K., \& Kaschak, M. (2021). Pointing to the Future of Language Research. Journal of Cognition, 4(1), 41. DOI: https://doi.org/10.5334/joc.162

Newmeyer, F. J. (1992). Iconicity and generative grammar. Language, 756-796. DOI: https://doi. org/10.1353/lan.1992.0047

Nuckolls, J. (1996). Sounds Like Life. New York: Oxford University Press.

Ozyurek, A. (2021). Considering the nature of multimodal language from a crosslinguistic perspective. Journal of Cognition, 4(1), 42. DOI: https://doi.org/10.5334/joc.165

Perlman, M., \& Woodin, G. (2021). A complete real-world theory of language should explain how iconicity remains a stable property of linguistic systems. Journal of Cognition, 4(1), 43. DOI: https://doi. org/10.5334/joc.166

Sidhu, D, M., \& Pexman, P. M. (2021). Implications of the "Language as Situated" View for Written Iconicity. Journal of Cognition, 4(1), 40. DOI: https://doi.org/10.5334/joc.159

Vigliocco, G., Perniss, P., \& Vinson, D. (2014). Language as a multimodal phenomenon: Implications for language learning, processing and evolution. Philosophical Transactions of the Royal Society of London. Series B, Biological Sciences, 369(1651), 20130292. DOI: https://doi.org/10.1098/ rstb.2013.0292

Vinson, D., Jones, M., Sidhu, D. M., Lau-Zhu, A., Santiago, J., \& Vigliocco, G. (2021). Iconicity emerges and is maintained in spoken language. Journal of Experimental Psychology: General. DOI: https://doi. org/10.1037/xge0001024

Zwaan, R. A. (2014). Embodiment and language comprehension: Reframing the discussion. Trends in Cognitive Sciences, 18(5), 229-234. DOI: https://doi.org/10.1016/j.tics.2014.02.008

TO CITE THIS ARTICLE: Murgiano, M., Motamedi, Y., \& Vigliocco, G. (2021). Situating Language in the Real-World: Authors' Reply to Commentaries. Journal of Cognition, 4(1): 44, pp. 1-4. DOI: https://doi.org/10.5334/ joc.181

Submitted: 20 July 2021 Accepted: 20 July 2021 Published: 23 August 2021

COPYRIGHT:

(c) 2021 The Author(s). This is an open-access article distributed under the terms of the Creative Commons Attribution 4.0 International License (CC-BY 4.0), which permits unrestricted use, distribution, and reproduction in any medium, provided the original author and source are credited. See http:// creativecommons.org/ licenses/by/4.0/.

Journal of Cognition is a peerreviewed open access journal published by Ubiquity Press. 